\title{
A Low-Cost, Smart AC Charging System for Electric Vehicle
}

\section{Bo Wang}

Shenzhen Power Supply Bureau Co., LTD, Shenzhen, China.

Email: iwangbo@yahoo.com.cn

Received September $10^{\text {th }}$, 2012; revised January $7^{\text {th }}$, 2013; accepted January $14^{\text {th }}, 2013$

Copyright (c) 2013 Bo Wang. This is an open access article distributed under the Creative Commons Attribution License, which permits unrestricted use, distribution, and reproduction in any medium, provided the original work is properly cited.

\begin{abstract}
In industry development strategy of electric vehicles, apart from concerns on the development of electric vehicles, we also need to consider the issue of charging facilities construction. Firstly, through analysis, this paper discusses the importance of AC charging points for electric vehicle development. By studying existing AC charging points on the market, it presents a low-cost smart AC charging system to reduce the cost investigated by power companies and operational bodies when laying of a large number of AC charging points. Compared with the conventional one, the proposed system has prominent features of low cost, small footprint and low investment.
\end{abstract}

Keywords: Electrical Vehicle; Charging Facility; AC Charging Point

\section{Introduction}

Chinese automobile production, with an average annual growth rate of $27.6 \%$, has surpassed the United States and Japan and has become the largest automobile producer and consumer in the world. However, the growth of Chinese traditional automobile is bound to increase our dependence on oil, and will further exacerbate the air pollution [1]. Chinese per capita possession of oil proven recoverable reserves is equal to only $7.7 \%$ of the world average. According to "BP World Energy Statistics 2009" [2], the world remaining proven reserves of crude oil in accordance with the 2008 annual extraction rate can also be mined for 42 years. Oil resources are depleting that constrained the development of the traditional vehicle. Chinese development and reform commission pointed out that Chinese current dependence on foreign oil had more than 52\% [3]. The development of electric vehicles will significantly reduce oil consumption and reduce environmental pollution. The efforts to develop electric vehicles are the only way to ensure sustainable development of Chinese automobile industry. From the above analysis, it is clear that environmental protection and energy security issues will enable China to develop electric vehicles [4,5]. At present, the number of electric vehicles used is small, the corresponding lack of charging infrastructure is also more, and there is a low return on investment in electric vehicle. However, the develop- ment of electric vehicles will have a breakthrough in the future. So, apart from concerns on electric vehicle development, we also need to consider the issue of charging facilities construction in industry development strategy of electric vehicles [6].

To implement the national energy saving policy, promotion of electric vehicle application, guide and standardize the constructing electric vehicle charging facilities of the China Southern Power Grid, China Southern Power Grid Co. Ltd developed a series of standards for electric vehicle charging technology as follows [7]:

1) $Q / C S G$ 11516.1-2010 General technical requirements for electric vehicle charging establishment;

2) Q/CSG 11516.2-2010 Code for design of electric vehicle charging station and charging point;

3) $\mathrm{Q} / \mathrm{CSG}$ 11516.3-2010 Technical specification for electric vehicle off-board charger;

4) Q/CSG 11516.4-2010 Technical specification for electric vehicle A.C. charging point;

5) Q/CSG 11516.5-2010 Specification of charging interfaces for electric vehicle off-board charger;

6) Q/CSG 11516.6-2010 Communication protocols between off-board charger monitoring unit and battery management system for electric vehicle;

7) Q/CSG 11516.7-2010 Technical specification for supervisor system of electric vehicle charging station;

8) Q/CSG 11516.8-2010 Code for acceptance of electric vehicle charging station and charging point. 
In 2010, China has adopted a recommended national standards (general technical requirements for electric vehicle charging stations), which lays the foundation for regulating and guiding the plan and design of electric vehicle stations in order to conduct energy supply infrastructure. These standards are of reference to electric vehicle charging stations of State Grid Corporation. By 2009, State Grid Corporation had developed a series of standards for electric vehicle charging stations:

9) Q/GDW 233-2009 Electric vehicle off-board charger general requirements;

10) Q/GDW 234-2009 Electric vehicle off-board charger specification for electrical interfaces;

11) Q/GDW 235-2009 Electric vehicle off-board charger communication protocols;

12) $\mathrm{Q} / \mathrm{GDW}$ 236-2009 Electric vehicle charging station general technical requirements;

13) Q/GDW 236-2009 Electric vehicle charging station guide of layout design;

14) Q/GDW 236-2009 Electric vehicle charging station power supply system criterion.

\section{The Importance of AC Charging Piles for EV}

The development of electric vehicles in China will gradually increase the demand for electric vehicle charging facilities. From Shenzhen Power Supply Bureau's operation analysis for the BYD E6 Taxi, in order to ensure the normal operation of the taxi companies, it generally needs to be charged with about $0.5 \mathrm{C}$ charging current. The rated voltage of its battery pack using $963.3 \mathrm{~V} / 200 \mathrm{Ah}$ batteries is about $316.8 \mathrm{~V}$, the nominal battery capacity is about $200 \mathrm{Ah}$ [8]. For the E6, $30 \mathrm{~kW}$ electric charging machine is probably needed to meet the needs for Shenzhen taxi operators.

The charging demand survey for electric taxi shows that while $90 \%$ users of electric vehicles would choose to charge their vehicles in two places: the parking lots and the home. For these users, they can use a slow charger. Generally, on board charger is used to charge the batteries of the electric vehicle. The charging time is usually 6 - 8 hours. The charging time is longer, but little damage to the batteries, compared with the rapid DC charge. So it can extend the life of batteries and can also reduce the impact on the power grid.

At present, the majority of our household electricity power is about $2 \mathrm{~kW}-5 \mathrm{~kW}$. However, the number of modern appliances and power consumption are increasing rapidly. The power consumption of many families has been close to the saturation power, even at night. The 2 - $3 \mathrm{~kW}$ charging power cannot be reserved for electric vehicles in most cases. And most of vehicles, especially in the city, are parked in a fixed area or commercial parking places, so their own existing AC power cannot be used for the electric vehicle charging. Moreover, there is also a great external cable security risk when charging Electric Vehicles.

While traditional power household appliances can be taken directly to a standard electrical plug, but electric vehicle charging is related to personal safety and protection, network communications, and many other issues, so if you want to meet the requirements of this part of consumers, the power companies and electric vehicles operating agency must provide AC charging piles to meet the national or/and enterprise standards. At present, in addition to national standards, the National Grid and Southern Power Grid have also introduced the corresponding technical specifications and standards for AC charging piles of electric vehicles.

For the convenient of electric vehicle users, slow charge piles can be constructed in the district, parking lots, shopping malls, and even in the roadside. Users can charge their electric vehicles using lots of slow charging piles during the day and the night. This method is less cost, but more effectiveness for our society.

\section{The Structure of Chinese Current AC Charging Piles}

As the demand for AC charging piles, many companies start to produce and sell slow AC charging piles in the market, and their general structure is shown in Figure 1. Through our analysis, the popular chargers include lots of modules, such as payment transactions, card readers, keyboards, display modules, printers and the corresponding drive modules, etc. [9].

\section{A Low Cost Smart AC Charging System}

\subsection{System Structure and Composition}

The block diagram of low-cost smart charging system is shown in Figure 2. It includes the following components:

1) Central server: the exiting servers of the power grid company can be used; they can also be bought.

2) Master machine: its functions are shown in Figure $\mathbf{3}$, including fees, printing, communication and other func-

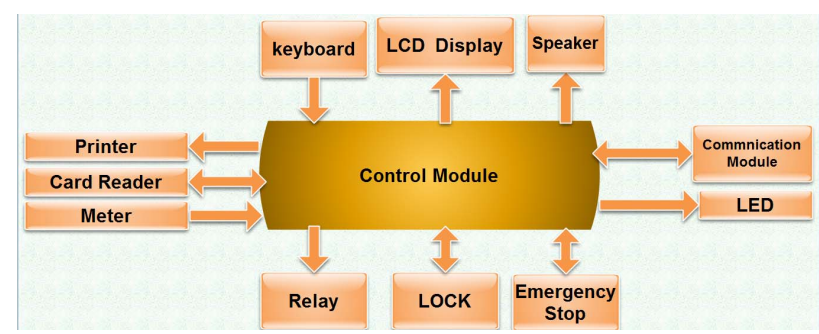

Figure 1. The structure of Chinese current AC charging piles. 
tions.

3) Slave machine: its functions are shown in Figure 4, including charging, metering and communications.

The system has following advantages:
1) Low cost: compared with the current charging point, each slaver machine does not need trading system, display module and printer because of sharing trading system. The shell size of system will be reduced. There are

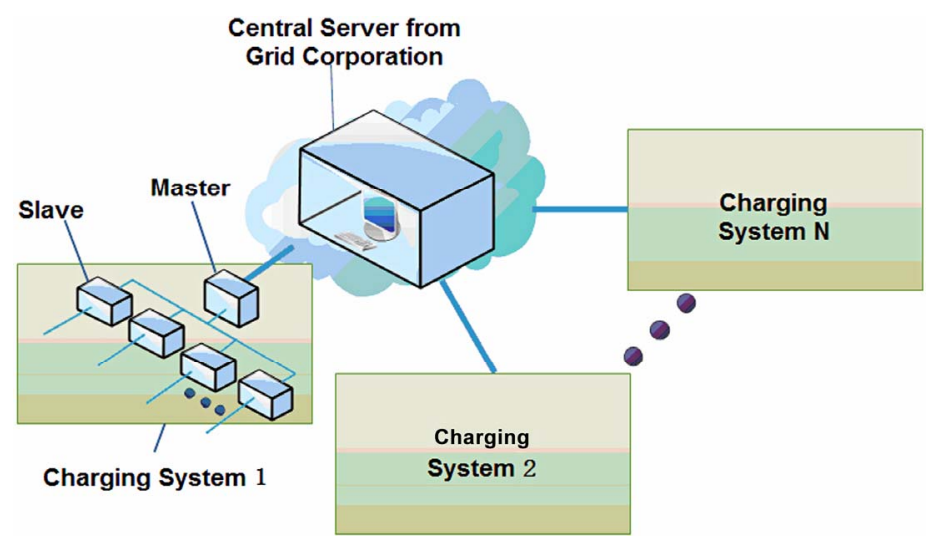

Figure 2. Low-cost smart charging system diagram.

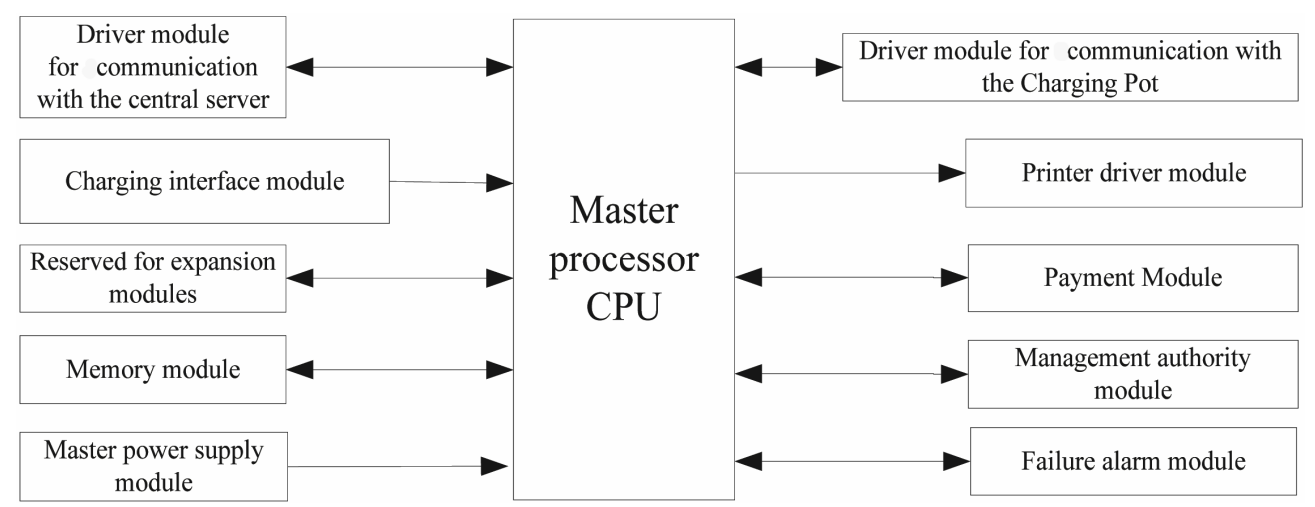

Figure 3. Master functional block diagram for low-cost smart charging system.

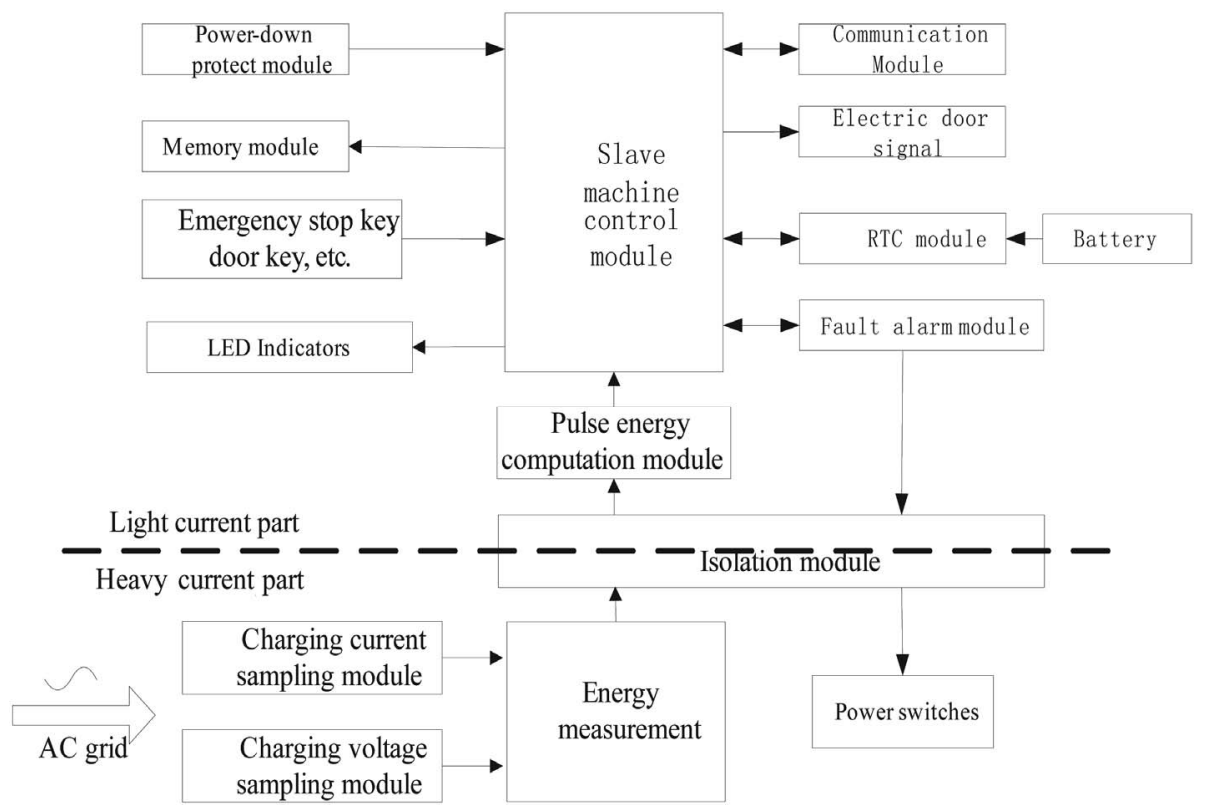

Figure 4. Slave machine functional block diagram for low-cost smart charging system. 
few functions in each slaver machine, thereby the cost of slave machine will be further reduced.

2) Small size: the size is small because each slave machine has few function modules.

3) Low investment: low cost and small construction area can greatly reduce the construction cost of charging facilities.

4) Ultra low standby power consumption: if the charging point is in standby status for long time, it will consume a lot of energy. Ultra low standby power consumption is designed to reduce the power consumption of each slaver machine.

5) Expansibility: more slave machines share a trading system, and the system reserves expansion interfaces.

6) Network communications: master machine has a network communication function, the data can be regularly uploaded to the central severs, and can be backed up on the local system as well.

7) Low maintenance and update cost: when maintaining and updating the whole system, the mater machine can only be maintained and updated. The cost will be greatly down.

\subsection{Payment Process of Charging}

Customers can easily pay for the charging fee according to Figure 5. The process is described as the following:

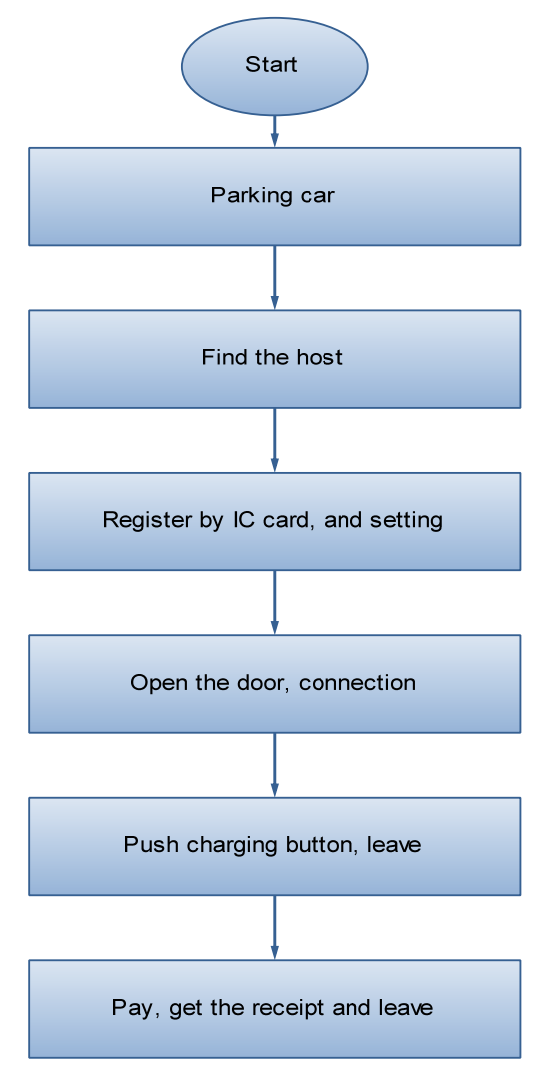

Figure 5. The payment process of charging.
1) Check the status of charging pile of parking spaces; park the car in the idle parking space. Find the host which manages the charging pile.

2) Register the charging pile by IC card and set the charging energy or the transaction amount (the setting of payment system based on the corresponding requirements of power supply bureau, the desired charging time also can be selected to ensure the full utilization of low power, and the cost of charging can be saved).

3) Open the door of the charging pile, connect the charger plug with the charging socket and shut the door of the charging pile.

4) Press the charging button if the charging indicator is lighting, and then the customer can leave.

5) Customer is needed to pay for the charging fee through the host. The transaction information is displayed and printed after the successful payment.

The above payment process of charging is only a simple of the charging system. In fact, the process can be designed according to different requirements.

\section{Conclusion}

Electric vehicles will be mass production in the future. Nowadays, the number of electric vehicles is small. The construction of charging facilities should be in low investment, many points. The ultimate goal of electric vehicle charging system is that all the parking places should be equipped with electric charging facilities. If these goals can be achieved, with the rapid development of key electric vehicles' parts, the electric vehicles will become the mainstream of the transport.

\section{REFERENCES}

[1] “Car Ownership.”

http://baike.Baidu.com/view/1379561.html

[2] BP, “BP Statistical Review of World Energy,” 2009.

[3] K. X. Xu, "Development and Reform Commission: China International Petroleum Dependence of 52\% Break through the Cordon,” People.

[4] B. Zhao and L. Gao, "Realistic Significance of Developing Electric Vehicles in China,” Today Keyuan, Vol. 20, 2010, p. 79.

[5] J. X. Liu, "Operability Analysis for Construction of Battery Swapping Station for Electric Vehicles,” Science and Technology Plaza, Vol. 3, 2010, pp. 226-229.

[6] “EV Charging Pot a Better Future," IT Manager World CEOCIO No. 302, 2010.

[7] “AC Electric Vehicle Charging Pot Technical Specifications," Company Standard for China Southern Power Grid Company Limited Q/CSG 11516.4-2010.

[8] BYD QCJ7006BEV Pure Electric Car Specifications.

[9] “AC Charging Pot for Electric Vehicles," Chinese Patent No. CN201020538652. 